Tagliabue L.C., Pasquinelli A., De Angelis E., Ciribini, A.L.C., Guzzetti, F. (2017). "GIS-based approach for district energy retrofit optioneering." In: LC3 2017: Volume I - Proceedings of the Joint Conference on Computing in Construction (JC3), July 4-7, 2017, Heraklion, Greece, pp. 129-136. DOI: https://doi.org/10.24928/JC3-2017/0269.

\title{
GIS BASED APPROACH FOR DISTRICT ENERGY RETROFIT OPTIONEERING
}

\author{
Lavinia Chiara Tagliabue ${ }^{1}$, Alice Pasquinelli ${ }^{2}$, Enrico De Angelis ${ }^{3}$, Angelo Luigi Camillo \\ Ciribini $^{4}$, Franco Guzzetti ${ }^{5}$
}

\begin{abstract}
Energy is a driver for buildings' refurbishment. The EU energy policies defined some strategies for nearly zero energy buildings ranging from envelope retrofit to the system efficiency enhancement. A GIS based approach is proposed to introduce a district level strategy to enable energy quality in the cities empowered by digital and computational technologies. A case study demonstrates how to assess different retrofit solutions into a sample district. The idea is to use the different data sources and define a common data environment in which data could be used to endorse different analyses on the same knowledge basis. The first step was to understand the level of detail and information required to describe in an accurate and fast way the energy performance related to buildings geometry and age. Two data packages have been tested: retrofit options were computed considering the more reliable data package model. Plausible retrofit scenarios related to the most suitable strategies have been tested to define energy quality to trigger for the district. The energy evaluation have been carried out by standard calculations on GIS-based information. The energy mapping is used to communicate results and possibly outline zones of intervention that can be managed through smart construction sites.
\end{abstract}

Keywords: BIM/GIS, energy retrofit optioneering, district energy refurbishment

\section{INTRODUCTION}

Built environment is required to be highly performative and guarantee improved standards of comfort. Safety, energy efficiency, static resistance and dynamic resilience, connectivity and smartness: constructions nowadays are expected to deliver customised services to enrich the user experience and enhance durability in the life cycle. Such a complex view of a smart asset management should be supported and delineated on the whole availability of data. Nevertheless, information on the existing building stock is fragmented into different databases and the data collection, that could be approximately easy for the new construction, is maze-like activity for existing assets. The digitalization of AEC sector shapes a future scenario where massive flux of information is provided by buildings, streets, infrastructures and objects: thus, the challenge is to manage to extract knowledge from this huge amount of information. For this reason, the fragmentation and relative

1 Research Fellow, Department of Information Engineering, University of Brescia, Brescia, Italy, lavinia.tagliabue@unibs.it

2 PhD student, Built environment and Construction Engineering Department, Politecnico di Milano, Italy, alice.pasquinelli@polimi.it

3 Full Professor, Built environment and Construction Engineering Department, Politecnico di Milano, Italy, enrico.deangelis@polimi.it

4 Full Professor, Civil, Environmental, Department of Architectural Engineering and Mathematics, University of Brescia, Brescia, Italy, angelo.ciribini@unibs.it

5 Associate Professor, Built environment and Construction Engineering Department, Politecnico di Milano, Italy, franco.guzzetti@polimi.it 
inconsistency of the information is a main concern. Urban data models are object-oriented data structure that can integrate BIM (Building Information Modeling) that will be adopted by local administration to up-date cadastral and the topographic database (TDB): thus a replicable and scalable methodology to be applied is the core research here proposed (Pasquinelli et al. 2016). The key issue is to use available information on Buildings to enhance an Information System that can afford and deliver a complete information on the Built Asset, to be used by multiple stakeholders which could enrich the system through new data sources (e.g. sensors, user' feedback, etc.). The energy issue is the driver (Nouvel et al. 2014) and improvement by retrofit strategies for a single building (Di Giuda et al. 2010) or extended on a district or city (Kaden and Kolbe 2013) is empowered by the digital approach. Energy needs can be calculated with a BIM based approach by means including thermal parameters for materials and spaces to perform energy analyses into a parametric way or defining simplified analytical models to be exported to detailed calculation engines or even by extracting structured information for steady-state calculation tools (e.g. datasheets) (Corrado et al. 2016). The key issue in these cases are the interoperability between geometrical model and energy model (Ciribini et al. 2015) and the accuracy of the results that could be invalidated by simplifications and procedure slip-up (De Angelis et al. 2015). The quality, level of detail and update version of the available information is also related to the energy purpose: savings potential, minimum requirement compliance, retrofit optioneering, energy auditing, energy certification, cost-optimality, etc.

The BIM/GIS oriented definition of the city database enables the Intelligent City Management System (Karakiewicz 2010) gradually linking traditional databases and new data sources. A case study (section 2) has been adopted to test the GIS-based energy retrofit optioneering: a district is used as test field for the methodology proposed in section 3. Different data sources have been integrated in the Information system and two data package with lower and higher level of detailed have been tested in previous research step (Tagliabue et al. 2016). The main data sources and data packages are described in section 3 however the analysis about energy retrofit has been performed on the more detailed data package with a level of detail and information derived by the available data sources and literature (Corrado et al. 2012).

\section{CASE STUdy District in GAVARDo, ITALY}

The case study used to apply the methodology for creating a Building Information System is a national testing area located in northern Italy in Gavardo, Brescia province. The study is promoted by Comunità Montana Valle Sabbia, a community of small municipalities, with the support of Secoval, a multi-utility company presently assisting the municipalities for services delivery and administrative responsibilities: a previous agreement between Politecnico di Milano and Comunità Montana Valle Sabbia enabled researchers to access public archives and data sources.

The case study area is a part of Gavardo city and a test on energy evaluation of the winter thermal need at district scale has been completed. The district is composed by 46 residential buildings and a percentage of about $22 \%$ of the sample buildings presented have both consumption data (i.e. energy bills) and energy labels (i.e. national certification). The district has been modeled into the GIS platform and the data exported to custom datasheets to calculate energy consumption, basing on reliable data package with varied levels of detail (namely DP1 and DP2). Data have been compared with energy certification and consumption for model calibration, as presented in previous papers (Tagliabue et al. 2016). Geo-referencing the energy consumption data or mapping the energy forecast with 
different retrofit scenarios would empower the identification of most energy-intensive buildings or districts and reveal the potential energy improvement.

\section{Methodology}

The adopted methodology starts in identifying the significant building data sources in the public archives. Then a proper analysis on data quality is due (Table 1) in order to detect strengths and weaknesses of available data and outline the correlation method for the existing information aiming at bridging the above mentioned fragmentation issue. Finally, the Gavardo case study is used as test field for the implementation of an information system aimed to analyse the suitability of data to address the evaluation of different energy retrofit options at a district scale.

The accuracy of data and the calculation model reliability have been compared to energy certifications available for the buildings included in the city sample considering the uncertainty of this data source, enabling the calibration of the energy calculation model. The model has been enriched with different databases and data extracted for the energy calculation into two data packages (DP1 and DP2) which have been tested to verify the reliability and accuracy of results (Figure 1).

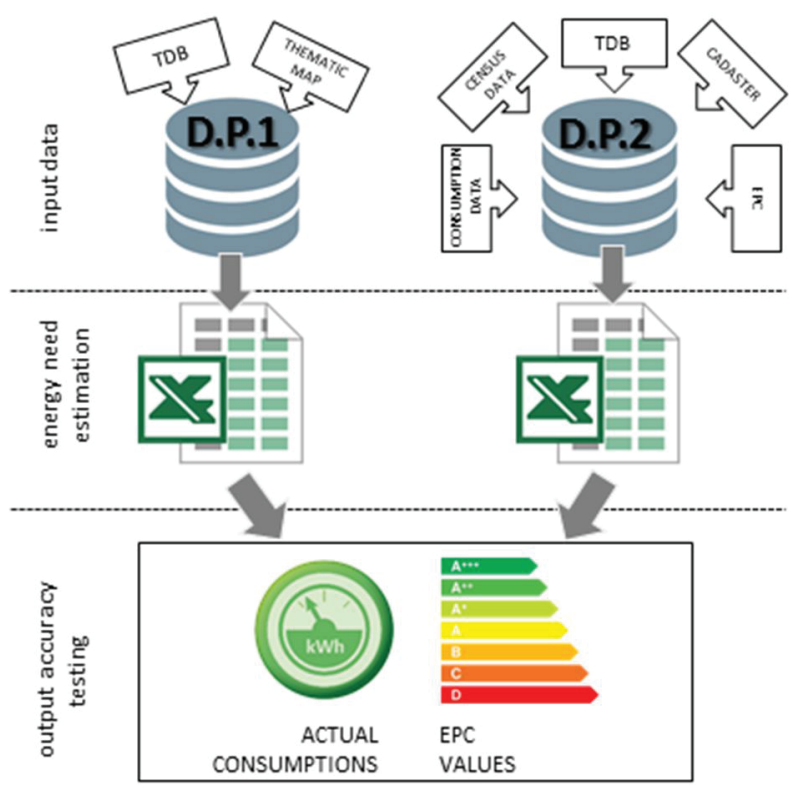

Figure 1: Energy estimation produced using different level of data enrichment

\subsection{Data packages and sources}

The analyses are calculated on the basis of information derived from the local Topographic Database (TDB), progressively improved in two step of data enrichment. These step are related to a specific defined Data Package (DP). The enrichment is progressive, such as the second step of data enrichment gets the contents coming from the previous steps adding more detailed information. Building data in the TDB derive from those characteristics that can be visually documented through stereo-pair images: buildings geometry is composed by parts having different elevation and heights corresponds to the eave: given these characteristics, building measures can be extracted directly from the TDB (e.g. gross volume and external surfaces). Roof shape is hardly reported in these tools. Semantic contents specify the main use of the building with no definition of minor functions with 
different energy patterns. Unfortunately, the year of construction in not stated in TDB, even if this is crucial data to derive thermal parameters of the envelope and thermal systems efficiency.

The first step, Data Package 1 or DP1 includes only rough data and technical energy assumptions in order to calculate the energy need. An approximate construction period can be roughly assigned to each building by spatially relating TBDs and existing thematic maps, such as land use cartographies (realized for environmental assessment purposes) and historical analyses on the progressive urbanization (typically produced for spatial planning purposes).

In Data Package 2 or DP2 more building data sources have been integrated to refine the information and improve the accuracy of the thermal results assessing the existing situation: hence, the data used for DP1 have been semantically enriched to configure DP2 adding data derived by existing archives (table 2). To this purpose, the process of linking the TDB data to other information though cadastral identifier ID and address has been completed. The sources of data used are reported in table 1.

Table 1: Data sources used for the data package definition.

\begin{tabular}{|c|c|c|}
\hline Data source & Description & Limitation \\
\hline $\begin{array}{c}\text { Topographic } \\
\text { Database (TDB) }\end{array}$ & $\begin{array}{l}\text { TDB is a georeferenced, object-oriented } \\
\text { representation of the territory given by } \\
\text { cartography. Every item has a self- } \\
\text { consistent 3D geometry with few semantics. }\end{array}$ & $\begin{array}{l}\text { No connection with } \\
\text { external data sources is } \\
\text { implemented. }\end{array}$ \\
\hline Cadastre & $\begin{array}{l}\text { Cadastre, the historic database concerning } \\
\text { buildings, is in charge of the national tax } \\
\text { agency. Its georeferenced part allows the } \\
\text { spatial overlap of TDB with real estate } \\
\text { specification. }\end{array}$ & $\begin{array}{l}\text { No automatic } \\
\text { procedure for the } \\
\text { quality check of } \\
\text { provided data }\end{array}$ \\
\hline Census data & $\begin{array}{l}\text { The family census form and a specific } \\
\text { building form are used by the national } \\
\text { institute of statistics (ISTAT) to collect data } \\
\text { about buildings. The data are similar to } \\
\text { cadastre so can integrate it however } \\
\text { potential informative redundancies can } \\
\text { occur. }\end{array}$ & $\begin{array}{l}\text { No geographic } \\
\text { reference, the address } \\
\text { is the only data } \\
\text { allowing identification } \\
\text { of the building and its } \\
\text { location }\end{array}$ \\
\hline $\begin{array}{l}\text { Energy consumption } \\
\text { data }\end{array}$ & $\begin{array}{l}\text { Electricity and gas consumption data are } \\
\text { reported for every Point of Delivery (POD) } \\
\text { registered in energy providers' databases } \\
\text { and set by local administration for yearly } \\
\text { financial controls. }\end{array}$ & $\begin{array}{l}\text { Restricted accessibility } \\
\text { due to privacy reasons. } \\
\text { The address is the only } \\
\text { geographic reference } \\
\text { to identify the } \\
\text { buildings }\end{array}$ \\
\hline $\begin{array}{l}\text { Energy Performance } \\
\text { Certification (EPC) } \\
\text { and thermal plants }\end{array}$ & $\begin{array}{l}\text { The data are available at regional level for } \\
\text { specific regulations and can be used to } \\
\text { verify energy estimation by different } \\
\text { calculation methods. The data have a fine } \\
\text { granularity connected to cadastre data. }\end{array}$ & $\begin{array}{l}\text { No public access } \\
\text { countrywide }\end{array}$ \\
\hline
\end{tabular}


Through a pre-processing of the existing information connected to the cadastral references (e.g. Energy Performance Certificates, thermal plants efficiency data, residents' data), the TDB augmented its building-related contents, enabling extra georeferenced and associated data: in fact building address has a key role to connect the asset to social and economic spheres and in the present work the availability of georeferenced consumption data is crucial (Tagliabue et al. 2016).

\subsection{Retrofit scenarios and calculation method}

The energy calculation method is based on national standards (UNI-TS 11300-1:2014): steady-state analysis is used to forecast the energy performance of the existing situation (DP2) and the thermal parameters are based on scientific assumption related to the year $\mathrm{f}$ construction (Corrado et al. 2012). The retrofit optioneering scenarios tested and visualized in the GIS-based energy mapping in section 4 are listed below and comply the current national energy requirement for refurbishment. The four energy retrofit scenarios are combined in a fifth progressive scenario including all measures. They are listed below with some performance specifications (Table 3):

- Insulation of the walls scenario $\left(\mathrm{U}=0.3 \mathrm{~W} / \mathrm{m}^{2} \mathrm{~K}\right)$;

- Roof insulation scenario $\left(\mathrm{U}=0.22 \mathrm{~W} / \mathrm{m}^{2} \mathrm{~K}\right)$;

- Window improvement scenario $\left(\mathrm{U}=1.9 \mathrm{~W} / \mathrm{m}^{2} \mathrm{~K}\right)$;

- Improved efficiency of the thermal plant with condensing boiler scenario;

- Progressive retrofit scenario including all measures.

Table 2: Assumption in DP1 and computable parameters in DP2

\begin{tabular}{|c|c|c|}
\hline Data & DP1 & DP2 \\
\hline number of floors & Constant storey height. & Actual number of floors \\
\hline $\begin{array}{l}\text { surface area to } \\
\text { volume ratio }\end{array}$ & $\begin{array}{l}\text { exposed surface and heated } \\
\text { volume }\end{array}$ & $\begin{array}{l}\text { Actual year of construction } \\
\text { Number of dwellings }\end{array}$ \\
\hline $\begin{array}{l}\text { gross heated } \\
\text { area }\end{array}$ & $\begin{array}{l}\text { The sum of each building part } \\
\text { footprint times the number of } \\
\text { floors }\end{array}$ & $\begin{array}{l}\text { Yearly electricity and gas } \\
\text { consumption registered }\end{array}$ \\
\hline $\begin{array}{l}\text { net heated } \\
\text { surface }\end{array}$ & $\begin{array}{l}\text { Calculated reducing the gross } \\
\text { surface by a } 15 \% \text { of the floor } \\
\text { surface }\end{array}$ & $\begin{array}{l}\text { number of people living inside the } \\
\text { buildings and demographic age } \\
\text { data concerning residents' }\end{array}$ \\
\hline $\begin{array}{l}\text { net heated } \\
\text { volume }\end{array}$ & $\begin{array}{l}\text { Net heated surface times a local } \\
\text { standard net storey height }\end{array}$ & $\begin{array}{l}\text { Division between heated and non- } \\
\text { heated parts of the building }\end{array}$ \\
\hline window surface & $\begin{array}{l}\text { the local standard window/floor } \\
\text { surface ratio }\end{array}$ & Different uses in the same building \\
\hline
\end{tabular}

\section{RESULTS}

The five scenarios compared to DP2 and energy quality is visualized in the GIS maps (Figure 1 - 4). It is possible to note that each scenario can partially improve the existing situation however, the progressive retrofit can reach high energy efficiency with energy saving ranging in average about $77 \%$ (minimum $37 \%$ and maximum $87 \%$ in the samples) 
and accomplishment a relevant mitigation of the peaks of inefficiency of the district (Figure 5).
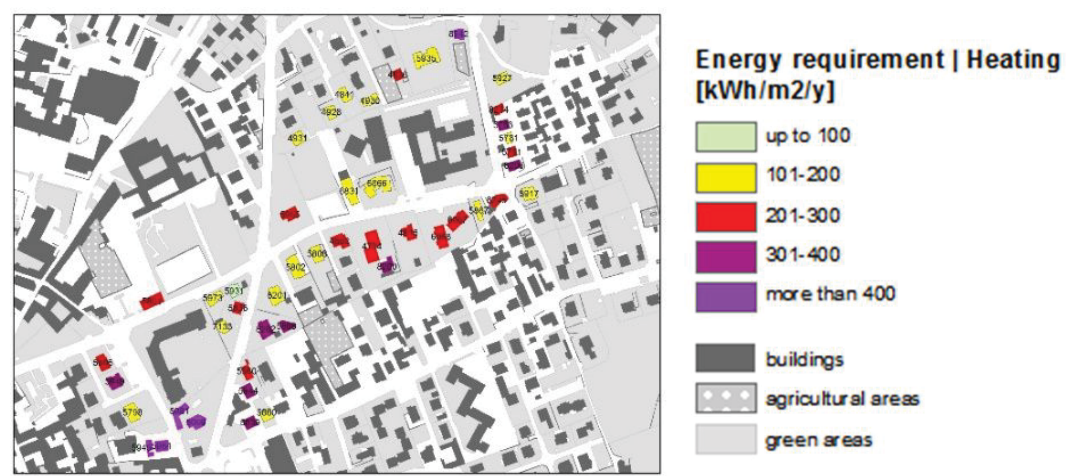

Figure 2: Primary energy calculated on the DP2 data.

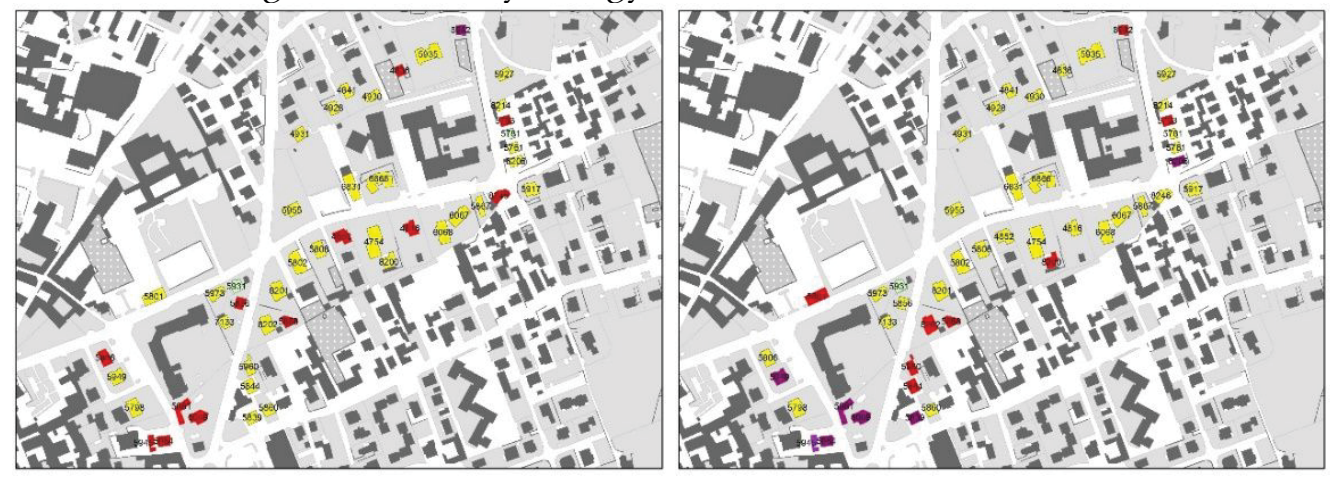

Figure 3: Wall insulation scenario and Roof insulation scenario

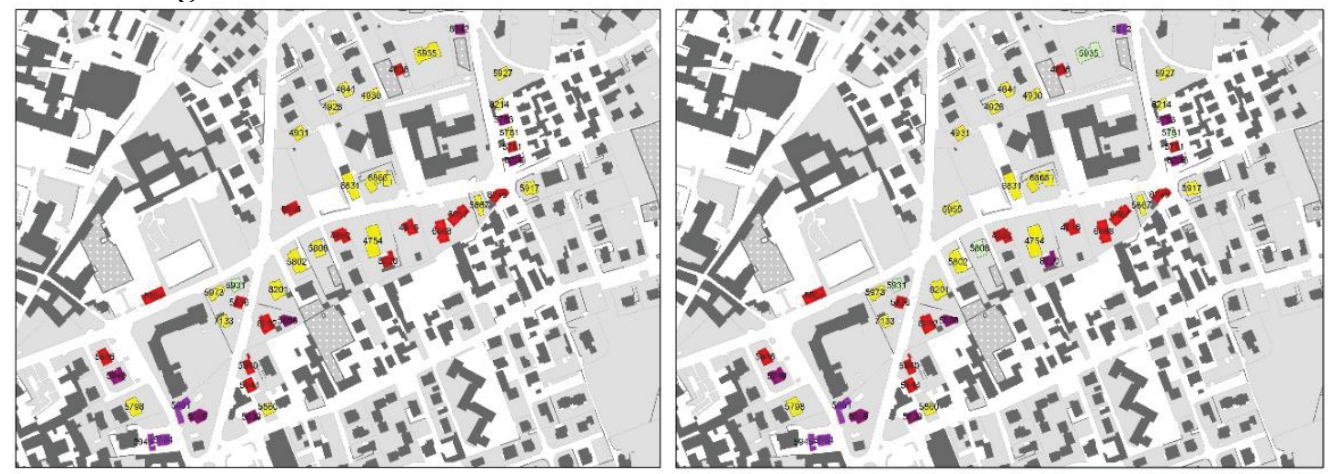

Figure 4: Windows improvement and Improved thermal plant.

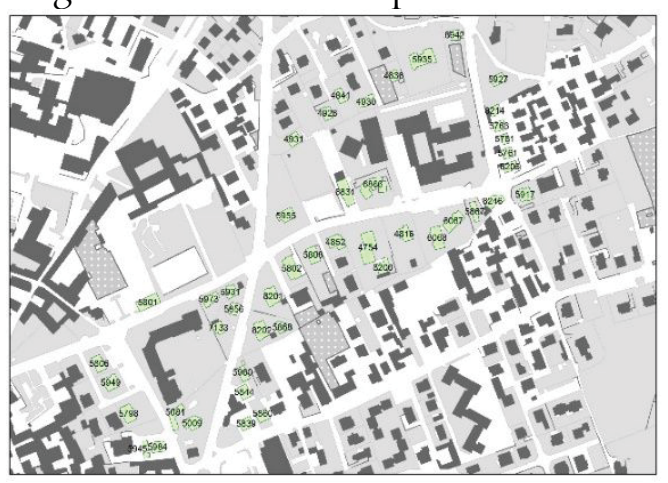

Energy requirement | Heating [kWh/m2/y]

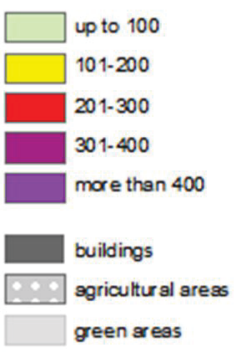

Figure 5: Progressive retrofit scenario.

The energy saving achievable with the different scenarios in the sample district is synthetized in table 4 . Based on the adopted assumptions and simplifications (i.e. no 
shading evaluation, equally window/wall ratio on the various orientations, forfeit evaluation of thermal bridges, etc.) in the Gavardo district, where the main part of the buildings have a low thermal resistance of the envelope, the more efficient single strategy is the wall insulation because of the most diffused residential use, which imply that there are not wide glazed surfaces and opaque envelope is prevalent.

Table 4: Energy savings achievable in the proposed scenarios

\begin{tabular}{cccc}
\hline Scenario & Average & Minimum & Maximum \\
\hline Insulation of the walls & $33 \%$ & $6 \%$ & $59 \%$ \\
Window improvement & $12 \%$ & $5 \%$ & $21 \%$ \\
Roof insulation & $25 \%$ & $6 \%$ & $48 \%$ \\
Improved efficiency (condensing boiler) & $25 \%$ & $21 \%$ & $32 \%$ \\
Progressive retrofit & $77 \%$ & $37 \%$ & $87 \%$ \\
\hline
\end{tabular}

The change of the thermal plant assuming a condensing boiler efficiency combined with existing emission and distribution sub-systems has a good energy saving varying of a $11 \%$ between the analysed cases while the roof insulation allows the same average improvement however with a variability of $42 \%$. The window replacement with high efficient products has the lower impact due to the low-rise residential typology of houses.

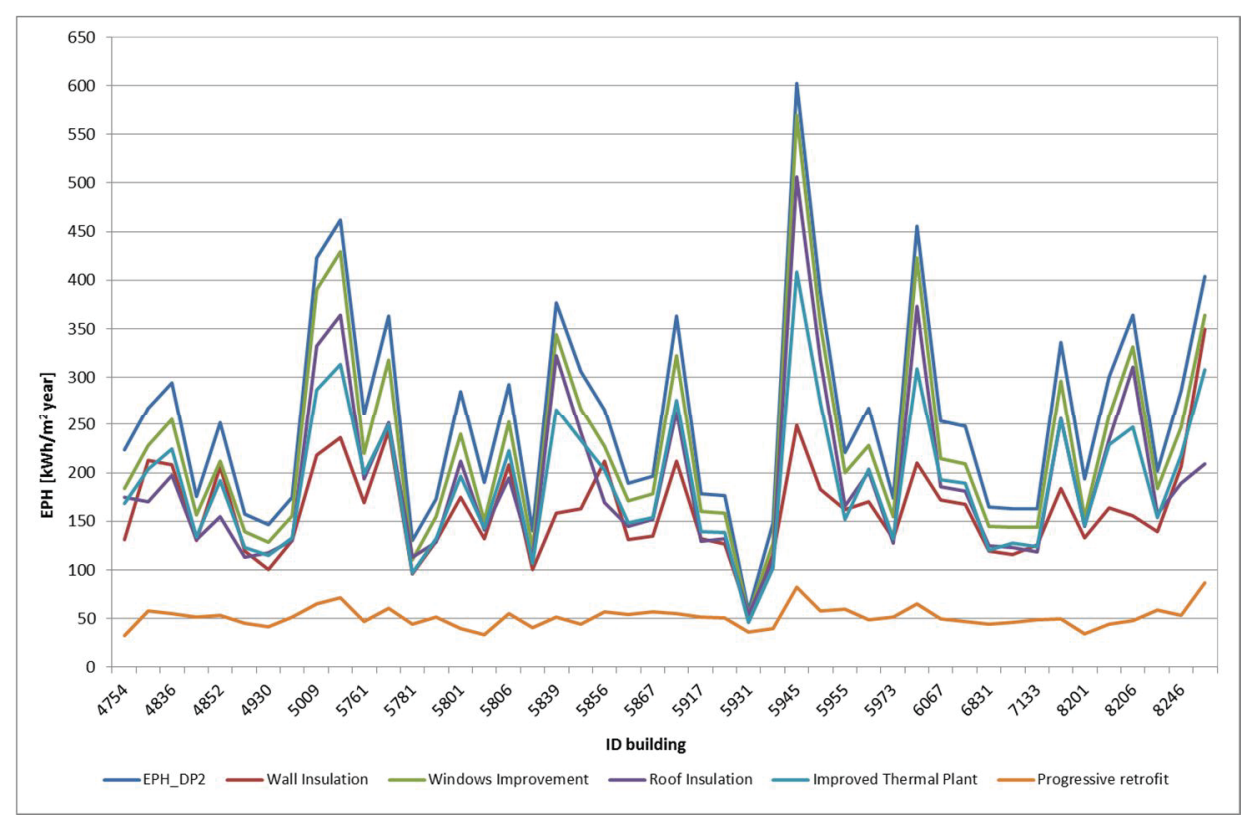

Figure 6: Progressive retrofit scenario.

\section{CONCLUSIONS}

The proposed GIS-based approach aims to provide procedures and tools to enable policies towards energy efficiency at city and district scale. The main scope of this type of application is to highlight a retrofit potential at macro scale that could help triggering a systemic renovation intervention at district/city scale. Of course, the actual implementation of possible retrofit strategies will require further and more detailed analysis: however, the provision of scenarios outlining the potential savings on a whole 
part of a city represents a starting point to involve and encourage possible stakeholders in the implementation of renovation policies (as in the EU programme OptEEmAL).

The BIM/GIS methodologies allow promoting a shared and collaborative environment to connect stakeholders and operators in different phase of the decision and operative process. The GIS platform can control and map different issues and different phases of the city development. The idea is to include a predictive models (e.g. surrogate models) of the energy performance based on technical or economic supported optioneering and define quality thresholds for the district/city that could be adopted through incentive programmes or included in preliminary assessment until construction site management.

\section{REFERENCES}

Corrado, V., Ballarini, I., Paduos, S. A. A. and Primo, E. (2016). The Energy Performance Assessment of nZEBs: Limitations of the Quasi-Steady State Approach. CLIMA 2016 12th REHVA World Congress Proceedings, Edited by Aalborg University, ISBN 8791606-31-4.

Corrado, V., Ballarini, I. and Corgnati, S. P. (2012). National scientific report on the TABULA activities in Italy. ISBN 978-88-8202-039-2.

Ciribini, A.L.C., De Angelis, E., Tagliabue, L.C., Paneroni, M., Mastrolembo Ventura, S. and Caratozzolo, G. (2015). Workflow of interoperability toward energy management of the building, ISTEA Conference on Environmental Sustainability, Circular Economy and Building Production.

De Angelis, E., Re Cecconi, F., Tagliabue, L.C., Maltese, S., Pansa, G., Torricelli, A. and Valagussa, S. (2015). Reliability of energy performance evaluations through different BIM and BEM models, ISTEA Conference on Environmental Sustainability, Circular Economy and Building Production.

Di Giuda, G.M., Valentina, V., De Angelis, E., Piantanida, P., Tagliabue, L.C. and Ciribini A.L.C. (2016) Progressive Energy Retrofit for the educational building stock in a Smart City, IEEE Second International Smart Cities Conference (ISC2 2016), Improving the citizens quality of life, 12-15 September 2016, Trento, Italy.

Kaden, R. and Kolbe, T. (2013). City-Wide Total Energy Demand Estimation of Buildings Using Semantic 3d City Models and Statistical Data. ISPRS Annals, II (November), pp.27-29.

Karakiewicz, J. (2010). Data driven urban design. Disruption, modeling and construction: changing dialogues, Proceedings of the XIV Congress of the Iberoamerican Society of Digital Graphics, SIGraDi. Universidad de los Andes, Bogotá, Colombia.

Nouvel, R., Zirak, M., Dastageeri, H., Coors, V. and Eicker, U. (2014). Urban energy analysis based on 3D city model for national scale applications, 5th German-Austrian IBPSA Conference, pp.83-90, 2014.

Pasquinelli, A., Pasini, D., Tagliabue, L.C., De Angelis, E., Guzzetti, F. and Ciribini, A.L.C. (2015). Energy Management of the Smart City through Information Systems and Models, International Conference ISTeA 2016, BACK TO 4.0: Rethinking the Digital Construction Industry, 30 June-1 J uly 2016, Naples, Italy.

Tagliabue, L.C., Pasquinelli, A., Di Giuda, G., Villa, V., Ciribini, A.L.C. and De Angelis, Cognitive Adaptive Urban Systems for the Living Built Environment, 2nd Annual International Conference on Urban Planning And Property Development (UPPD 2016) Copyright @ GSTF 2016 doi: 10.5176/0000-0000_UPPD.43, pp. 141-150.

UNI/TS 11300-1:2014 Prestazioni energetiche degli edifici - Parte 1: Determinazione del fabbisogno di energia termica dell'edificio per la climatizzazione estiva ed invernale. 